$2^{\text {nd }}$ International Conference Art, Illustration and Visual Culture in Infant and Primary Education

\title{
The Campaign for Drawing
}

Eileen Adams keynote speaker

\section{abstract}

\section{Introduction}

\section{Purposes of drawing}

The Campaign for Drawing in the UK has two main drivers. The Big Draw is an annual public event-based programme: Power Drawing is an educational thread running through the Campaign. The two are complementary and mutually supportive. A strong symbiotic relationship exists between them and it is difficult to separate their impact. Each has raised the profile of the importance of drawing within different constituencies: each has influenced how different people perceive drawing and how they use it. Or do they represent two polarities, each pulling in a different direction, resulting in a creative tension, and giving rise to an energy that fuels development? This paper reflects on the intertwining filaments of research and development that have promoted drawing as a medium for learning.

Keywords: drawing, learning.

The Campaign for Drawing was launched in 2000 by The Guild of St George, to celebrate the centenary of John Ruskin, a nineteenth century English artist, critic and educator. Since then, the Campaign has become an independent charity, developing a groundswell of interest in the use of drawing as a medium for engagement, participation and learning in a variety of settings: in schools, museums, galleries, heritage sites and community activities.

The Big Draw, an annual month-long nationwide festival of drawing, has shown that drawing can be a positive collaborative activity as well as a private passion. It has established a higher profile and greater popular support for drawing, addressing the issue that although greater numbers of people visit museums and galleries, not every social group participates equally (Hewison and Holden 2004). The rapid growth from 188 Big Draw events in 160 venues in the UK in 2000 to 1100 events in 1000 UK venues in 2011, as well as 30 events in 20 overseas locations, has been achieved by the Campaign's inclusive nature and its clear message that drawing is for everyone. Annual Drawing Inspiration Awards $<$ www.campaignfordrawing.net/the-bigdraw/ehos > celebrate Big Draws to inspire others. The website showcases examples <http:// campaignfordrawing.net/the-big-draw>

Through its Power Drawing education and professional development programmes, the Campaign has produced powerful evidence and arguments to support learning through drawing, created a focused and serious regard for drawing as a medium for learning in schools and informal education, and provided training for educators to embed the use of drawing in their everyday practice. < www.campaignfordrawing.net/power-drawing $>$

Drawing is infinitely versatile. It can symbolise power and authority in a royal seal or it can be a shout of protest in scrawled graffiti. It can represent a person or a place, evoke a feeling or an atmosphere, create a memory or a dream, record observed reality or shape imagined fantasy. It can make the invisible visible, accessible and usable. It can be exploratory, investigatory, 
2nd International Conference Art, Illustration and Visual Culture in Infant and Primary Education $2^{\circ}$ Congreso Internacional

Arte, Ilustración y Cultura Visual en Educación Infantil y Primaria
${ }^{\circ}$ Congresso Internacional

de Arte, llustração e Cultura Visual

na Educação Infantil e Primária

questioning. It can attempt to fix experience and create a trace, a memory or a memorial. It can formulate a vision of the future. Drawing is an intellectual and physical activity that links sensing, feeling, thinking and doing. Drawing can be about form, space or time, a quick sketch on the back of an envelope or a set of technical specifications carefully worked out on a computer. It can deal with analysis or synthesis. Drawing can show cause and effect. It can enable us to explore details of everyday experience, construct a narrative or contemplate issues of life or death. Drawing is the primal means of symbolic communication, which predates and embraces writing and functions as a tool of conceptualization parallel with language (Petherbridge 2010).

Numeracy and verbal literacy are key in developing our capacity to understand experience, to think, and to participate in the concrete world of objects and experiences, as well as in the abstract world of ideas. Visual and spatial literacy are also important in developing the intellectual survival kit to enable us to prosper in an increasingly complex world, to be inventive and creative. So much of our material culture depends on drawing - the complex range of environments, products, communications and systems that support and shape contemporary life could not be brought into existence without it. Just as teachers have a responsibility to nurture verbal literacy across the curriculum, they also have a responsibility to develop their pupils' visual literacy. Words and numbers codify information. They enable us to shape ideas and communicate thoughts. Drawing uses visual codes and conventions to do the same things. Like words and numbers, it makes thought visible, accessible and capable of manipulation. In essence, drawing makes you think!

\section{Drawing in schools}

In UK secondary schools, drawing is used in a range of subjects, but it is not given sufficient attention or used as effectively as it might. This is surprising, when students spend at least $10 \%$ of teacher-directed time drawing (Rinne 1999), and probably a lot more in addition to that. Drawing is now a recognised element in the inspection process in primary schools. Ofsted inspectors look for evidence of drawing from memory, observation and imagination. The challenge for the teacher is to know how to support learning through drawing. Much is expected of primary teachers, and their level of confidence to work with drawing is low. OFSTED inspectors report that teachers' subject expertise in drawing varied widely. Their lack of confidence in their own drawing abilities meant they were reluctant to demonstrate drawing techniques to pupils and to assess pupils' performance. However, they noted positive evidence that quality and confidence in drawing evolved through challenging drawing activities in project work, and that drawing was approached regularly and adventurously, linking lessons with work created outside school. Inspectors recommended that schools should increase pupils' confidence and creativity in drawing by widening the repertoire of teaching approaches, including teaching adventurous drawing for all (Ofsted 2012)

\section{Power Drawing}

Power Drawing has encouraged teachers to use drawing more effectively to support learning in a range of curriculum areas, to develop more creative approaches to learning and teaching, as well as prompt more purposeful approaches to drawing.

The most powerful educational experience is to have the excitement and satisfaction of applying both skill and knowledge to achieve a worthwhile goal. It is in the PURPOSEFUL application of both skill and knowledge that the true relevance of education is made clear (Baynes 2010).

A key contribution has been to show how drawing can help develop thinking skills, through illuminating various purposes and uses of drawing as a medium for learning. For instance, drawers may wish to understand something for themselves. These drawings make use of personal imagery or symbols and may make sense only to the drawer - drawing as perception. Drawers may wish to communicate information or ideas to others. Here they need to adopt codes or conventions that the person attempting to read the drawing can understand - drawing as communication. It may be that drawers start drawing with only a vague idea of the subject matter or intention, but through drawing, ideas take shape and are developed and refined drawing as invention. Sometimes, drawers will want to make something happen as a result of their drawing - a plan to make something or to do something - drawing as action. Drawing is presented not as a set of discrete skills and techniques: rather it is seen as a way of prompting 
gresso Internacional

Arte, llustração e Cultura Visual

na Educação Infantil e Primária

different kinds of thinking, emphasizing the importance of ideational thinking, as well as conclusive thought (Rosenberg 2008).

Power Drawing has also encouraged the view that drawing to learn promotes positive attitudes, enabling the child to reflect on and re-work experience to understand the world, and to experiment, imagine and invent it anew. Both approaches prompt creative thinking. Drawing helps children deal positively with the experience of frustration and failure: these are part of the learning experience. You re-work your drawing, you modify it, you can even erase your past mistakes, or you can screw it up, throw it away and start again. Drawing contributes powerfully to the development of aesthetic and design sensibility. It obliges you to be discriminating and make informed choices in the choice of techniques and the use of media. Drawing with others develops social skills of empathy and collaboration.

\section{Publications}

Analysis, synthesis and critique of the use of drawing as a medium for learning have been documented in Power Drawing publications, a series of 12 books that demonstrate how different people use drawing, and which explain the purposes of drawing as part of the learning process (Adams 2001-2011). They are packed with ideas, explanations and advice. They show convincingly how drawing supports different kinds of thinking, with examples of drawings by children, young people and professionals such as artists and designers. In addition, two packs are specifically designed for primary schools. Another pack, contains four books and a DVD with 16 films. The books focus on drawing, primarily with adults, on heritage sites: the DVD shows evidence of The Big Draw in action.

Most importantly, the publications argue that different kinds of drawing promote different kinds of thinking. They identify types of drawing and explain the varied purposes that drawing serves. They concentrate on the idea of drawing shaping the learning process, rather than drawings that result from the process of learning. The publications make it clear that you can both learn to draw and draw to learn. Children's drawing is valued and celebrated, but it is also interrogated and critiqued in the same way as drawing by adults, to illuminate its usefulness as a medium for learning.

Case studies on the Campaign's website celebrate the efforts of educators in a variety of settings. They show a range of opportunities for drawing in various kinds of cultural and educational programmes. They demonstrate the transferability of ideas and strategies across cultural sectors, and even across national borders. They reinforce the Campaign's message that drawing is not just for children, it is for everyone. Through wide dissemination of these publications and case studies, educational thinking is shared between educators and institutions, between different professional groups and between different cultural sectors.

\section{Professional development programme}

The Power Drawing professional development programme has provided courses for teachers, artists and other educators to extend their knowledge of drawing and to understand its various purposes in the context of learning. They are helped to identify opportunities for learning through drawing in their work. They understand more fully how to stimulate and support drawing activities and to identify criteria for evaluation. Most importantly, this programme provides a pedagogical framework to underpin drawing activities in schools and other settings. Participants are invited to document their experience through images of children engaged in drawing activities, examples of children's drawings and through interpretative commentaries. They review each other's work, offering encouragement and support, suggesting ideas and ways of using drawing for different purposes. They value the opportunity to reflect on their experience and to develop their ability to articulate their practice. They talk not only about the satisfactions and achievements, but also about the challenges, frustrations and disappointments.

Following the training programmes, participants report that the range of drawing strategies they use is far greater than at the beginning, encompassing a variety of purposes, including not only communication, but also perception and invention. Importantly, drawing is used to develop group work and nurture social skills of collaboration, negotiation and shared decisionmaking. Children are encouraged to experiment and to be thoughtful about the purposes of 
${ }^{\circ}$ Congresso Internacional

de Arte, llustração e Cultura Visual

na Educação Infantil e Primária

their drawing, their choice of media and their use of particular techniques. Teachers find that drawing improves children's motivation and their capacity to learn, as well as enhancing their enjoyment of learning. They see that it can help raise educational standards. They witness how it develops children's visual and spatial understanding, as well as facilitating the development of the imagination and powers of invention. They discover that it has an important role to play in developing verbal literacy skills. They are adamant that it is for all pupils, not only for those pupils supposedly gifted and talented, or those who are disaffected or disadvantaged.

Educators report that they themselves develop a higher level of confidence both in drawing and in supporting learning through drawing. They identify a number of changes in their practice, such as introducing a wider range of drawing strategies, creating more opportunities for experimentation and reflection, using drawing to prompt and shape thinking, rather than to illustrate and summarise what has been learned. They see drawing as a means of learning, rather than as a discrete technical skill. Artists report that they develop fresh perspectives on drawing, as well as a wider range of skills to support learning that they are able to use in a variety of situations, working with schools, museums and in community settings. For some, it gives new impetus to their artistic practice (Adams 2009).

\section{Conclusions}

The Big Draw has established itself as a fixture in cultural and community calendars, with a recognised name and identity. It has given permission for experimentation with drawing, and shown how drawing can be used to nurture social interaction and participation in a range of activities from face painting to consultation for environmental change. Drawing is generally seen as a private, personal and reflective activity, yet The Big Draw has demonstrated that it can be public, interactive and celebratory. It has created a positive and informed public perception of drawing as engaging and exciting, particularly in museums and galleries, as well as on heritage sites. It has created a critical mass of support for drawing. It has emphasized the value of drawing in the context of playful learning and collective creativity. It has shown that drawing is not just for children, but can involve people of all ages, who bring different kinds of experience and knowledge to the activity, as well as different levels of skill. It offers opportunities for learning.

The Power Drawing programme has used an action research model, concerned with changing and improving professional practice. Investigation allows experiment. Case studies provide evidence. Peer review ensures an exchange of experience and ideas, and opportunities for reflection and evaluation. Training days provide stimulus and a framework for change, and encourage teachers to be more articulate about their practice, with participants acting as critical friends. Work-based research, supported by peer-review, developed within a clear pedagogical framework, and resulting in the production of a resource, supports development of the use of drawing as a medium for learning in schools.

I am not persuaded that Power Drawing has offered any new approaches to education. I am not sure that it has devised any experimental pedagogy. I am not convinced that it has created any new knowledge about drawing. However, it has certainly developed a fresh understanding of the value of drawing as a significant element in the learning process. It has articulated its importance in developing skills of perception, communication, invention and action. It has impacted on policy by establishing a new relevance for areas of skill and knowledge as well modes of thinking that were in danger of being lost in the British education system. It has extended the range of learning strategies available to educators. It has revisited well known and well established approaches to learning, and obliged educators in a range of settings to reconsider a familiar activity they perhaps take for granted, and to invest it with new meaning. Drawing - making marks, making meaning. The Campaign for Drawing, through its public event programme and it education and professional development programmes, has put drawing back on the agenda! 
Fig. 1. Big Draw at the British Library, Londonv

Figure 2. Big Draw at The Lightbox, Woking
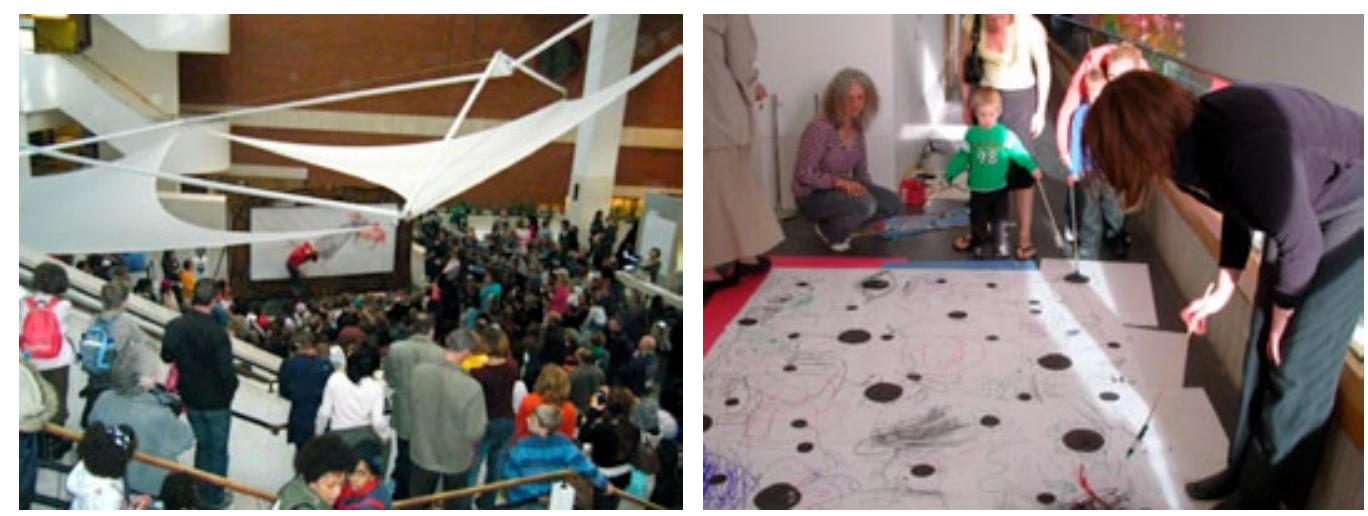

Fig. 3. Big Draw at the Picasso Museum, Barcelona

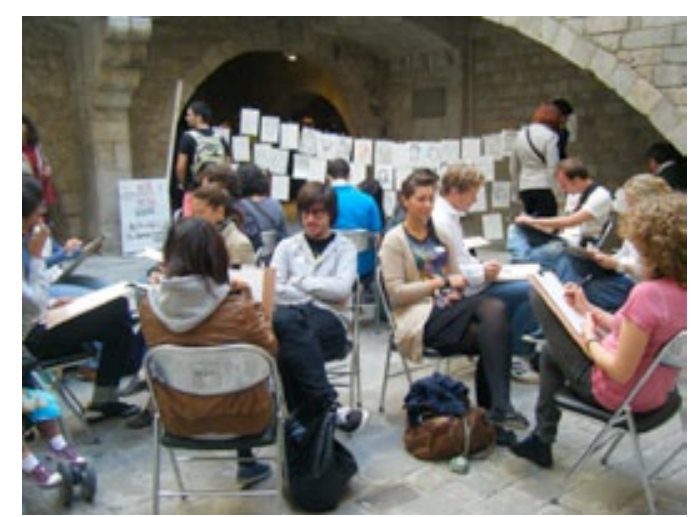

\section{THE CAMPAIGN FOR DRAWING: PRIMARY SCHOOLS}

Fig. 4. Drawing as perception: observational drawing of a shell by 6 year old

Fig. 5. Drawing as communication: pictorial map, My Square Mile

Collaborative drawing by 10 year olds
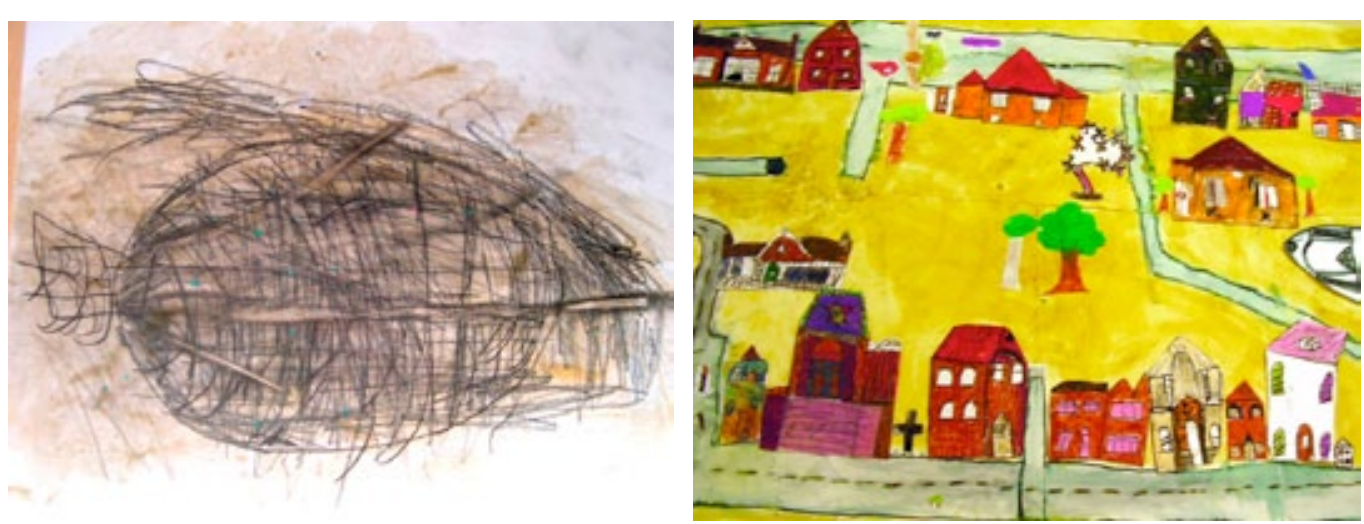

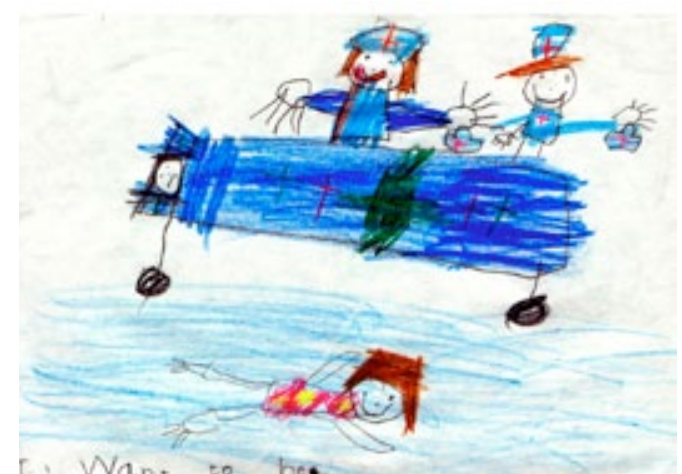


(n)

Art, Illustration and Visual Culture in Infant and Primary Education
Arte, llustración y Cultura Visual en Educación Infantil y Primaria de Arte, Ilustracão e Cultura Visual

na Educação Infantil e Primária

3. THE CAMPAIGN FOR DRAWING: SECONDARY SCHOOLS

Fig. 7. Drawing as perception: landscape by 14 year old

Fig. 8. Drawing as communication: portrait by 17 year old
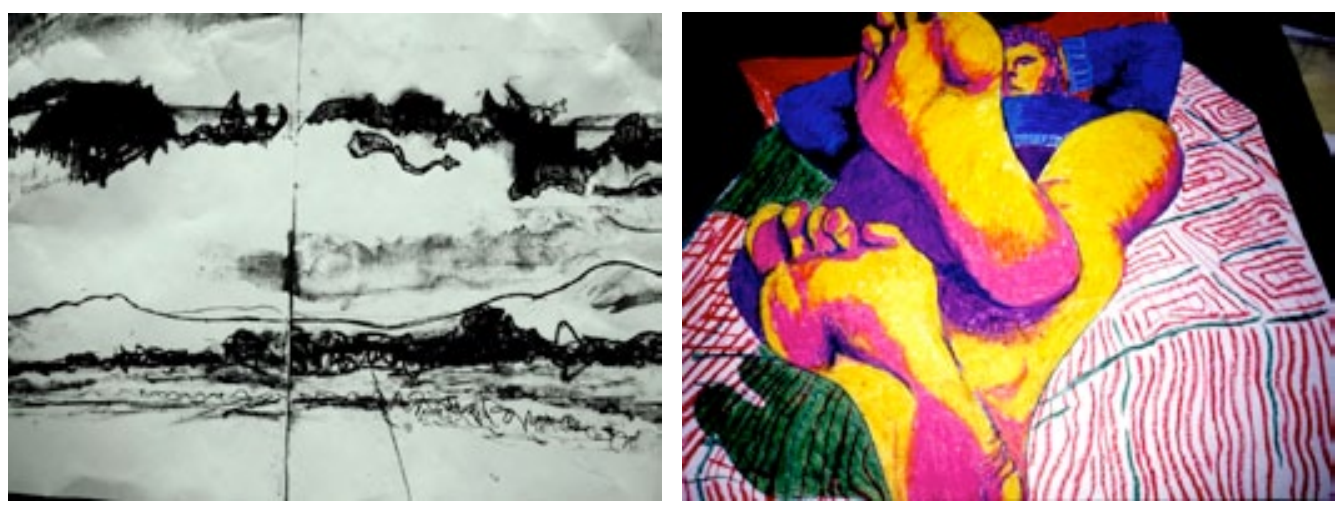

Fig. 9. Drawing as invention: digital drawing, design for new development by 18 year old

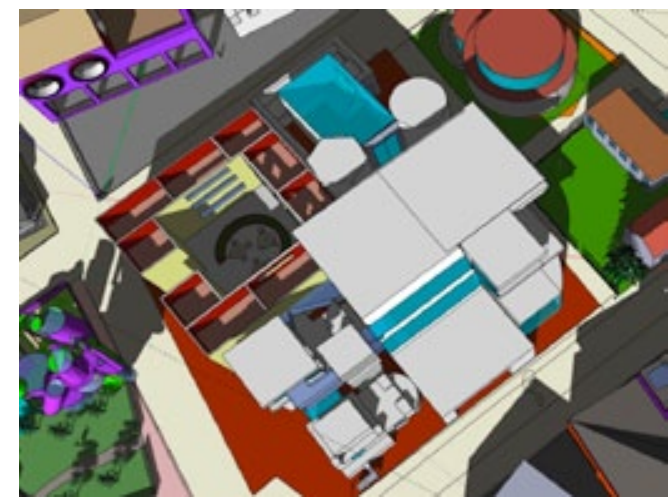

4. THE CAMPAIGN FOR DRAWING: EDUCATORS

Fig. 10. Educators experiment with blind and sighted drawing

Fig. 11. Teachers and artists report on work in schools for peer review
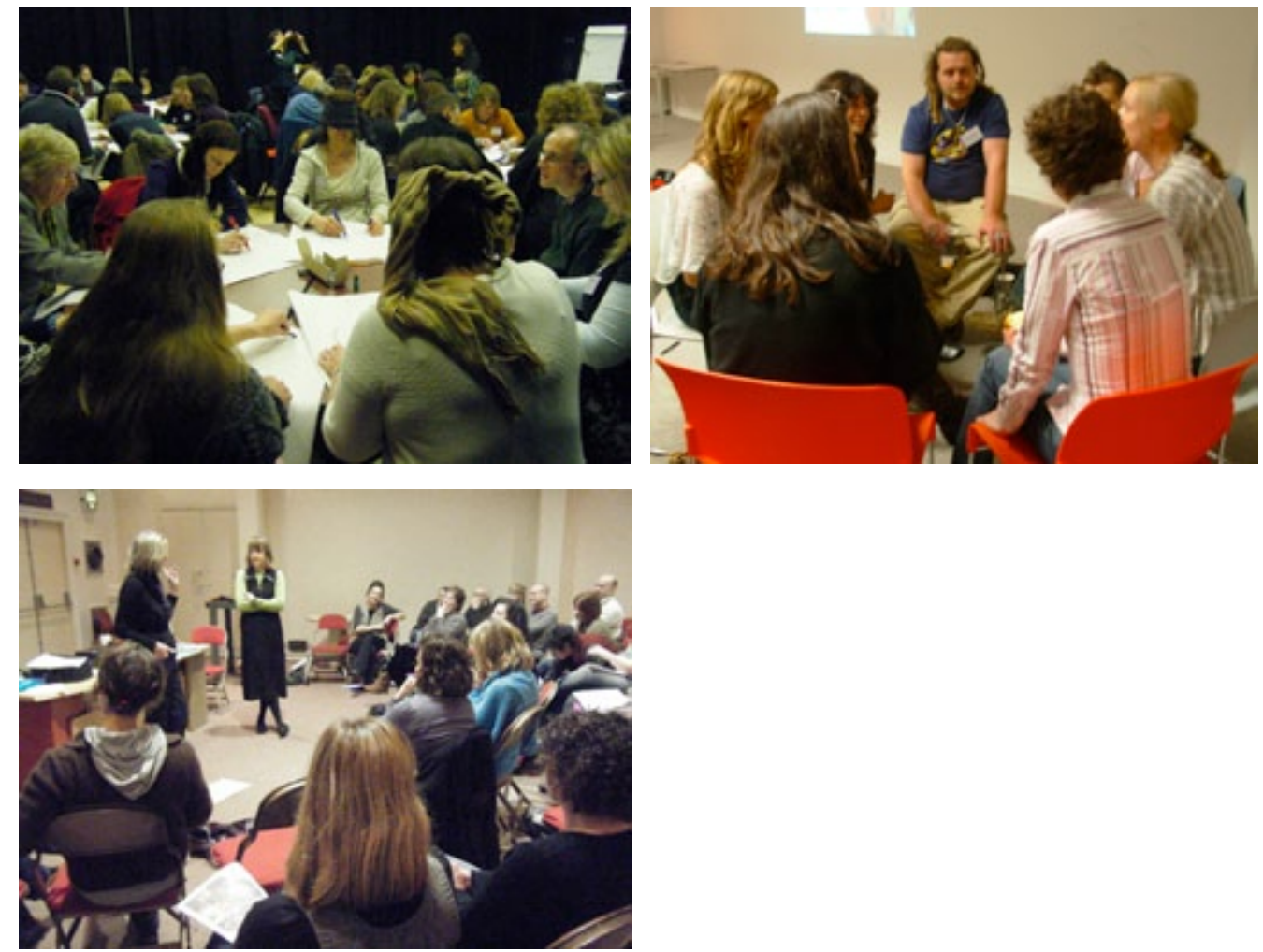
$2^{\text {nd }}$ International Conference

Art, Illustration and Visual Culture in Infant and Primary Education $2^{\circ}$ Congreso Internacional

Arte, llustración y Cultura Visual en Educación Infantil y Primaria
Congresso Internaciona

de Arte, llustração e Cultura Visual

na Educação Infantil e Primária

\section{THE CAMPAIGN FOR DRAWING: DISSEMINATION}

Fig. 13. Power Drawing publications, http://www.campaignfordrawing.org/ resources/publications.aspx

Fig. 14. Eileen Adams talking about the use of sketchbooks http://www. weareoca.com/photography/makinglogs/

Fig. 15. Eileen Adams explaining drawing as perception, communication, invention and action http://www. youtube.com/watch?v=1e6ruFp7isU the-most-of-sketchbooks-and-learning-
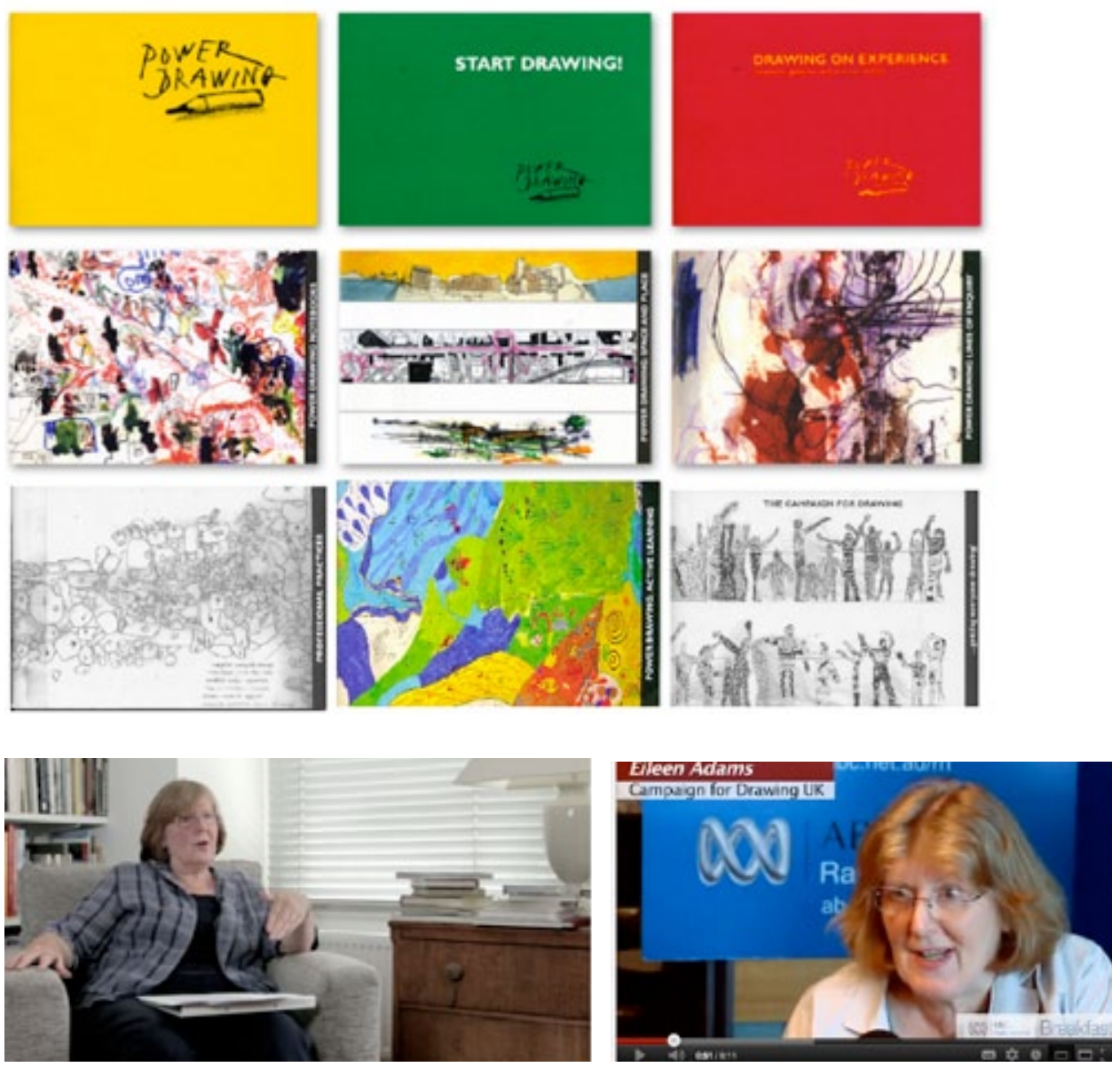

Images 1-13 Eileen Adams; image 14 Mark Lomas; image 15 abc.net.au.rn.breakfas

\section{Bibliographical references}

Adams E. (2001-2011) Power Drawing series of publications, The Campaign for Drawing.

Adams E. (2009) Power Drawing: Active Learning, Evaluation Report CD file 1, The Campaign for Drawing.

Baynes K. (2010) Models of Change: The future of design education, John Eggleston Memorial Lecture, Design and Technology Education: An International Journal 15.3

Hewison R. and Holden J. (2004) The Right to Art: Making Aspirations Reality, Demos.

Rosenberg T. (2008) New Beginnings and Monstrous Births: Notes Towards an Appreciation of Ideational Drawing, in Garner S. Writing on Drawing, Intellect.

Ofsted (2012) Making a mark: art, craft and design education, Ofsted.

Petherbridge (2010) The Primacy of Drawing: Histories and Theories of Practice, Yale University Press.

Rinne P. (1999) An investigation of drawing across the National Curriculum at Key Stage 3, unpublished PhD study, University of Surrey, Roehampton. 